\title{
Characterization of KPC-Producing Serratia marcescens in an Intensive Care Unit of a Brazilian Tertiary Hospital
}

Roumayne L. Ferreira't ${ }^{1 \dagger}$, Graziela S. Rezende ${ }^{1 \dagger}$, Marcelo Silva Folhas Damas ${ }^{1 \dagger}$, Mariana Oliveira-Silva², André Pitondo-Silva², Márcia C. A. Brito ${ }^{3}$, Eduardo Leonardecz', Fabiana R. de Góes ${ }^{4}$, Emeline Boni Campanini ${ }^{1}$, Iran Malavazi ${ }^{1}$, Anderson F. da Cunha ${ }^{1}$ and Maria-Cristina da Silva Pranchevicius ${ }^{1 *}$

OPEN ACCESS

Edited by:

Filipa Grosso,

University of Porto, Portugal

Reviewed by:

Martina Barchitta,

University of Catania, Italy

Daria Van Tyne,

University of Pittsburgh, United States

${ }^{*}$ Correspondence:

Maria-Cristina da Silva

Pranchevicius

mcspranc@gmail.com

tThese authors have contributed equally to this work

Specialty section: This article was submitted to

Antimicrobials, Resistance

and Chemotherapy,

a section of the journal

Frontiers in Microbiology

Received: 28 October 2019

Accepted: 21 April 2020

Published: 20 May 2020

Citation:

Ferreira RL, Rezende GS

Damas MSF, Oliveira-Silva M,

Pitondo-Silva A, Brito MCA,

Leonardecz E, Góes FR,

Campanini EB, Malavazi I,

da Cunha AF and Pranchevicius

M-CS (2020) Characterization

of KPC-Producing Serratia marcescens in an Intensive Care Unit

of a Brazilian Tertiary Hospital.

Front. Microbiol. 11:956.

doi: 10.3389/fmicb.2020.00956
${ }^{1}$ Departamento de Genética e Evolução, Universidade Federal de São Carlos, São Carlos, Brazil, ${ }^{2}$ Programas de Pós-graduação em Odontologia e Tecnologia Ambiental, Universidade de Ribeirão Preto, Ribeirão Preto, Brazil, ${ }^{3}$ Laboratório Central de Saúde Pública do Tocantins, Palmas, Brazil, ${ }^{4}$ Instituto de Ciências Matemáticas e de Computação, Universidade de São Paulo, São Carlos, Brazil

Serratia marcescens has emerged as an important opportunistic pathogen responsible for nosocomial and severe infections. Here, we determined phenotypic and molecular characteristics of $54 \mathrm{~S}$. marcescens isolates obtained from patient samples from intensive-care-unit (ICU) and neonatal intensive-care-unit (NIUC) of a Brazilian tertiary hospital. All isolates were resistant to beta-lactam group antibiotics, and 92.6\% (50/54) were not susceptible to tigecycline. Furthermore, 96.3\% showed intrinsic resistance to polymyxin $E$ (colistin), a last-resort antibiotic for the treatment of infections caused by MDR (multidrug-resistant) Gram-negative bacteria. In contrast, high susceptibility to other antibiotics such as fluoroquinolones (81.5\%), and to aminoglycosides (as gentamicin 81.5\%, and amikacin 85.2\%) was found. Of all isolates, $24.1 \%$ were classified as MDR. The presence of resistance and virulence genes were examined by PCR and sequencing. All isolates carried KPC-carbapenemase (b/a $\left.a_{K P C}\right)$ and extended spectrum beta-lactamase blaTEM genes, $14.8 \%$ carried bla $O X A-1$, and $16.7 \%$ carried bla $C T X-M-1$ group genes, suggesting that bacterial resistance to $\beta$-lactam antibiotics found may be associated with these genes. The genes SdeB/HasF and SdeY/HasF that are associated with efflux pump mediated drug extrusion to fluoroquinolones and tigecycline, respectively, were found in $88.9 \%$. The aac $\left(6^{\prime}\right)-\mathrm{lb}-\mathrm{cr}$ variant gene that can simultaneously induce resistance to aminoglycoside and fluoroquinolone was present in $24.1 \%$ of the isolates. Notably, the virulence genes to (i) pore-forming toxin (Sh/A); (ii) phospholipase with hemolytic and cytolytic activities (Ph/A); (iii) flagellar transcriptional regulator (F/hD); and (iv) positive regulator of prodigiosin and serratamolide production (PigP) were present in $98.2 \%$. The genetic relationship among the isolates determined by ERIC-PCR demonstrated that the vast majority of isolates were grouped in a single cluster with $86.4 \%$ genetic similarity. In addition, many isolates showed $100 \%$ genetic similarity to each other, suggesting that the $S$. marcescens that circulate in this ICU are closely related. Our results suggest that the antimicrobial resistance to many drugs 
currently used to treat ICU and NIUC patients, associated with the high frequency of resistance and virulence genes is a worrisome phenomenon. Our findings emphasize the importance of active surveillance plans for infection control and to prevent dissemination of these strains.

Keywords: Serratia marcescens, intensive care units, KPC, virulence and resistance genes, ERIC-PCR

\section{INTRODUCTION}

Serratia marcescens is a Gram-negative bacillus that naturally resides in the soil and water and produces a red pigment at room temperature. Although previously considered non-pathogenic, this species has emerged as a prominent opportunistic pathogen found in nosocomial outbreaks in neonatal intensive care Units (NICUs), intensive care units (ICUs) and other hospital units over the last few decades (Enciso-Moreno et al., 2004; Moradigaravand et al., 2016; Ghaith et al., 2018).

The true occurrence of $S$. marcescens is still underestimated (Zingg et al., 2017). In NICUs, studies have showen that infected newborns are a potential source of $S$. marcescens (Cristina et al., 2019), although there is a constant increase of S. marcescens bacteremia across all age groups (Vetter et al., 2016; Phan et al., 2018). S. marcescens increasingly adapts to hospital environments (Yoon et al., 2005; Gastmeier, 2014). It accounts for $15 \%$ of all isolates from nosocomial infections (Raymond and Aujard, 2000). Although it is difficult to identify the source of $S$. marcescens during outbreaks, it is the third most frequent pathogen identified (Gastmeier et al., 2007), and more than one clone can be usually identified (David et al., 2006; Montagnani et al., 2015; Dawczynski et al., 2016).

Serratia marcescens associated with hospital outbreaks or epidemic events are commonly resistant to several antibiotics (Moradigaravand et al., 2016; Cristina et al., 2019). In fact, one important feature of S. marcescens is its resistance to narrow-spectrum penicillins and cephalosporins; nitrofurantoin; tetracycline; macrolides; cefuroxime; cephamycins; fluoroquinolone, and colistin (Stock et al., 2003; Liou et al., 2014; Moradigaravand et al., 2016; Sandner-Miranda et al., 2018). The resistance to some of these molecules may be intrinsic to this specie and is explained by either the presence of resistance genes on the chromosome or by the acquisition of such genes via horizontal transfer. It is noteworthy that the latter mechanism is considered the most important event that leads to multiple antibiotic resistance (von Wintersdorff et al., 2016; Sandner-Miranda et al., 2018).

Extended-spectrum $\beta$-lactamases (ESBLs) are a group of bacterial enzymes that can be rapidly transferred via plasmid exchange (Rawat and Nair, 2010) causing resistance to a broad range of $\beta$-lactams (Naas et al., 2008). Carbapenemases are the most versatile family of $\beta$-lactamases able to hydrolyze carbapenems and many other $\beta$-lactams (Jeon et al., 2015) including penicillins, cephalosporins, and monobactams (Anderson et al., 2007; Marschall et al., 2009). In general, bacteria carrying the bla $a_{K P C}$ and/or ESBLs genes usually harbor other resistance genes associated with several classes of antimicrobials (Tzouvelekis et al., 2012; Cao et al., 2014; Ribeiro et al., 2016).
Since S. marcescens has been acquiring a range of ESBLs and commonly exhibit co-resistance to many other classes of antibiotics, the infections caused by these multidrug-resistant (MDR) isolates impair therapy and limit treatment options ( $\mathrm{Yu}$ et al., 1998; Mostatabi et al., 2013; Herra and Falkiner, 2018).

In this study, we investigated the phenotypic characteristics regarding antimicrobial resistance and the genotypic traits of S. marcescens isolated from a tertiary care hospital's ICUs including the search for resistance and virulence genes as well as the genetic relationship among the isolates. Our report describes MDR profile and KPC-producing S. marcescens isolates and highlight the importance of monitoring $S$. marcescens infection and the need of constant surveillance to support continuous and effective measures to prevent the spread of these strains.

\section{MATERIALS AND METHODS}

\section{Study Design and Bacterial Isolates}

From February 2014 to June 2015, a total of 54 S. marcescens were isolated of clinical specimens collected from 45 patients admitted to intensive-care-unit (ICU) and neonatal intensive care unit (NICU) of a tertiary care government hospital in Palmas, Tocantins, Brazil. Since 2013, there has been an increase in detection of S. marcescens isolates from hospital inpatients, and in 2015, the hospital reported an apparent $S$. marcescens outbreak that occurred from July to August 2015. Appropriate intervention measures were established, such as reviewing the infection control policies, hand antisepsis practices and determination of trends of isolation of $S$. marcescens over time. To trace the source of the infection, bacteria were isolated from various samples obtained from clinical indications of infections during the patients' ICU stay.

As part of the control measures, surveillance cultures were obtained from tracheal aspirate and rectal swabs from all ICU patients, on admission (within the first $24 \mathrm{~h}$ ) and during the stay (once a week). Blood, wound, catheter tip, drain, sputum, urine, rectal swab, and tracheal aspirate samples were primarily sent to the hospital's laboratory, processed and cultured by standard microbiological techniques. The blood samples were inoculated first in blood culture bottles (Hemoprov-NewProv, Brazil). All clinical samples, including blood culture bottles giving positive signals were cultured onto MacConkey agar (Probac, Brazil), blood agar (Probac, Brazil), and chocolate blood agar (Probac, Brazil). Plates were incubated at $37^{\circ} \mathrm{C}$ for up to $48 \mathrm{~h}$. S. marcescens were identified by Gram staining, cultural characteristics in MacConkey agar (Probac, Brazil), blood agar (Probac, Brazil), and biochemical tests (Bactray I, II,III; Laborclin, Brazil). The antimicrobial susceptibility profile 
was determined by Kirby-Bauer disk diffusion method. All $S$. marcescens isolates and the microbiological reports prepared at the hospital were sent to the Central Laboratory of Public Health of Tocantins (LACEN-TO) for further phenotypic validations.

\section{Bacterial Identification and Antimicrobial Susceptibility Test}

Once samples were received at LACEN, bacterial identification and antimicrobial susceptibility tests were performed by the Vitek 2 system (Biomerieux, France), according to Clinical and Laboratory Standards Institute guidelines (CLSI, 2019). All 54 S. marcescens isolates were screened for susceptibility against 16 antimicrobial agents: ampicillin (AMP), ampicillin/sulbactam (SAM), piperacillin/tazobactam (TZP), cefuroxime (CXM), cefoxitin (FOX), ceftazidime (CAZ), ceftriaxone (CRO), cefepime (FEP), ertapenem (ETP), imipenem (IPM), meropenem (MEM), amikacin (AMK), gentamicin (GEN), ciprofloxacin (CIP), tigecycline (TGC), and colistin (CST). Broth microdilution method was performed to determine tigecycline and colistin minimum inhibitory concentration (MICs) and results were interpreted based on the European Committee on Antimicrobial Susceptibility Testing (EUCAST, 2018) criteria, available at https://www.eucast.org/fileadmin/src/media/PDFs/EUCAST_ files/Breakpoint_tables/v_8.1_Breakpoint_Tables.pdf. All isolates were tested for carbapenemase production by Modified Hodge test, synergy test and ethylenediaminetetraacetic acid (EDTA) test under the CLSI guidelines (CLSI, 2019) as described elsewhere (Miriagou et al., 2010; Nordmann et al., 2011; Okoche et al., 2015; Ferreira et al., 2019). Multidrug-resistance S. marcescens isolates were classified by non-susceptibility to at least one agent of three or more antimicrobial categories (Magiorakos et al., 2012). S. marcescens is intrinsically resistant to AMP, SAM, CXM, FOX, and CST; therefore, these antibiotics were not included in the MDR classification (Magiorakos et al., 2012).

\section{Genomic DNA Extraction}

Isolates of $S$. marcescens were subcultured on Brain Heart Infusion (BHI) agar (Oxoid, United Kingdom) and incubated for $24 \mathrm{~h}$ at $37^{\circ} \mathrm{C}$. All samples were submitted to genomic DNA extraction using the Wizard Genomic DNA Purification Kit (Promega, Madison, WI, United States), according to manufacture's instructions.

\section{Detection of Antibiotic-Resistance}

Polymerase chain reaction (PCR) was performed for detection of $\beta$-lactamase genes (bla $a_{T E M}$, bla $a_{S H V v a r i a n t s}, b l a_{O X A-1}, 4$ and 30, bla $a_{C T X-M-1 \text { group }}$ ), carbapenemase genes (bla $a_{K P C}, b l a_{I M P}$, bla $a_{V I M}, b l a_{N D M}, b l a_{O X A-48}$ ) (Ferreira et al., 2019), plasmid mediated quinolone resistance (PMQR) gene (aac(6')-Ib-cr) (Wong et al., 2014; Mitra et al., 2019), resistance-nodulationdivision (RND) efflux pumps ( $S d e \mathrm{~B}, S d e \mathrm{Y}$ ), and outer membrane gene (HasF, a TolC homolog) involved in energy-dependent efflux of antimicrobial agents (Kumar and Worobec, 2005b). The genes were amplified using specific primers designed to follow the conditions described in the references from Table 1. All primers were synthesized by Exxtend (Brazil). Amplicons were analyzed by gel electrophoresis in $1.0 \%$ agarose and visualized under ultraviolet (UV) light.

\section{Virulence Gene Detection}

The presence of four virulence genes were assessed by PCR: genes PigP, a positive regulator of prodigiosin and serratamolide production; FlhD, a flagellar transcriptional regulator; ShlA, a pore-forming toxin with hemolytic activity; PhlA, a phospholipase A with hemolytic activity. The primers sequences amplicon sizes and annealing temperatures are listed in Table 1. Amplicons were analyzed by gel electrophoresis in $1.0 \%$ agarose and visualized under ultraviolet (UV) light.

\section{Sequence Analysis of Antibiotic-Resistance Markers and Virulence Genes}

One amplicon of each studied gene was randomly selected for confirmation of identity by DNA sequencing using an automated sequencer (ABI 3500xL Genetic Analyzer; Applied Biosystems, Foster City, CA, United States). After amplification, we extracted the PCR products from agarose gels using the Illustra GFX PCR DNA (GE Healthcare), which were purified using the Gel Band Purification Kit (GE Healthcare), both according to manufacturer's instructions. Obtained sequences were edited with Bioedit v7.0.5 (Hall, 1999), compared with the $\mathrm{nr}$ database using the Blastn tool ${ }^{1}$ and submitted to the GenBank database. Genes and their respective accession numbers: $b l a_{C T X}-$

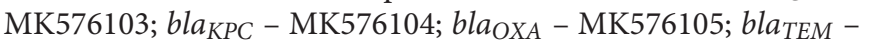
MK576106; SdeB - MN583232; SdeY - MN583233; HasF MN583234; aac(6')-Ib-cr - MN583235; FlhD - MN583236; PigP - MN583237; ShlA - MN583238; PhlA - MN583239). Access to genetic heritage was approved by the National System for the Management of Genetic Heritage (SisGen $n^{\circ}$ AFF27ED).

\section{Enterobacterial Repetitive Intergenic Consensus Polymerase Chain Reaction}

Enterobacterial repetitive intergenic consensus PCR (ERICPCR) analysis was performed to evaluate the genetic similarity among the $54 \mathrm{~S}$. marcescens isolates using the primers and conditions previously described by Versalovic et al. (1994). PCR reactions were performed using the enzyme TaKaRa Ex Taq DNA Polymerase (Takara Bio, Kusatsu, Japan). The BioNumerics program version 5.1 (AppliedMaths, Keistraat, Belgium) was used to construct the unweighted pair group mean method (UPGMA) similarity dendrogram with Dice's similarity coefficient, following Ferreira et al. (2019).

\section{Statistical Analyses}

In the analysis of contingency tables, we used Fisher's exact test and/or Barnard's exact test. Maximum likelihood did not present superior efficiency in relation to the previous methods (data not show). It was used logistic regression model with two predictor variables $x_{1}$ and $x_{2}$. Statistical software $\mathrm{R}$ was used in all data analysis.

\footnotetext{
${ }^{1}$ https://blast.ncbi.nlm.nih.gov/
} 
TABLE 1 | Sequences of primes used for detection of resistance markers.

\begin{tabular}{|c|c|c|c|c|}
\hline Gene & Sequence $\left(5^{\prime}-3^{\prime}\right), F / R$ & TM ( $\left.{ }^{\circ} \mathrm{C}\right)$ & Amplicon size (bp) & References \\
\hline blakPC & СTTGTCATCCTTGTTAGGCG & & & \\
\hline bla $a_{T E M}$ & TCGTCGTITGGTATGGCTTC & & & \\
\hline \multirow[t]{2}{*}{ bla $_{C T X}-M-1$ group } & ACAGCGATAACGTGGCGATG & 64 & 216 & Li and Li, 2005 \\
\hline & TCGCCCAATGCTITACCCAG & & & \\
\hline blasHVvariants & ATCCCGCAGATAAATCACCAC & & & \\
\hline \multirow[t]{2}{*}{ blaoxA-1 } & GGCACCAGATTCAACTTTCAAG & 63 & 563 & Dallenne et al., 2010 \\
\hline & GACCCCAAGTTTCCTGTAAGTG & & & \\
\hline \multirow[t]{2}{*}{ blaoXA-48 } & GCGTGGTTAAGGATGAACAC & 55 & 438 & Poirel et al., 2011 \\
\hline & CATCAAGTTCAACCCAACCG & & & \\
\hline blaIMP & CTACCGCAGCAGAGTCTTTGC & 55 & 587 & Martins et al., 2007 \\
\hline \multirow[t]{2}{*}{$b l a a_{N D M}$} & GCAGCTTGTCGGCCATGCGGGC & 60 & 782 & Doyle et al., 2012 \\
\hline & GGTCGCGAAGCTGAGCACCGCAT & & & \\
\hline \multirow[t]{2}{*}{$m c r-1$} & CGGTCAGTCCGTTTGTC & 51.6 & 309 & Liu et al., 2015 \\
\hline & CTTGGTCGGTCTGTAGGG & & & \\
\hline \multirow[t]{2}{*}{$\operatorname{aac}\left(6^{\prime}\right)-1 \mathrm{~b}-\mathrm{cr}$} & ATGACTGAGCATGACCTTGC & 55.4 & 519 & Platell et al., 2011 \\
\hline & TTAGGCATCACTGCGTGTTC & & & \\
\hline \multirow[t]{2}{*}{ SdeB } & AGATGGCCGATAAGCTGTTG & 55.4 & 200 & Hornsey et al., 2010 \\
\hline & CAGCGTCCAGCTTTCATACA & & & \\
\hline \multirow[t]{2}{*}{ SdeY } & TCCATCAACGAAGTGGTGAA & 55.5 & 200 & Hornsey et al., 2010 \\
\hline & GTTATCGAGAAGCCGAACG & & & \\
\hline HasF & CATGTCGAAATGGCGCCAAC & 57.5 & 785 & Hornsey et al., 2010 \\
\hline \multirow[t]{2}{*}{ PhIA } & GGGGACAACAATCTCAGGA & 55.4 & 207 & Aggarwal et al., 2017 \\
\hline & ACGCCAACAACATACTGCTTG & & & \\
\hline
\end{tabular}

\section{Ethical Considerations}

In our study, we did not use/collect human genetic material and biological samples. Strains were part of the collection of the Central Laboratory of Public Health, (LACEN-TO), a health-care facility that is a reference in diagnosis in the state of Tocantins, Brazil. It was a retrospective study, and epidemiological data were obtained from a database or similar, which will be kept confidential in accordance with the with the terms of Resolution 466/12 of the National Health Council. These epidemiological data were also provided by LACEN-TO. Informed consent was not required according to resolution 466/12 concerning research involving humans of the National Health Council (Conselho Nacional de Saúde/Ministério da Saúde, Brasília, Brazil, 2012). The study was approved by the Committee of Ethics in Human Research of the Federal University of São Carlos (no. 1.088.936). Permission to conduct the study was also obtained from the
Health Department of the State of Tocantins (Secretaria de Saúde do Estado do Tocantins - SESAU) and LACEN/TO.

\section{RESULTS}

\section{Serratia marcescens Isolates}

A total of 54 S. marcescens strains were isolated from 39 ICU and 6 NICU patients' samples at a tertiary hospital located in city of Palmas, Tocantins state. In six patients, 5 from ICU and 1 from NCIU, S. marcescens was isolated in more than one infection site. The prevalence of $S$. marcescens strains by age group was the following: $0-1$ day $(12.96 \% ; n=7), 18-59$ years $(38.89 \%$, $n=21), 60$ years or more $(48.15 \%, n=26)$. The median age of patients was 57.0 years (range, 0-93 years). S. marcescens strains were more frequently found in male $(68.5 \%, n=37)$ 
than in female $(31.5 \%, n=17)$ patients (Figure 1A). Fortythree samples $(79 \%)$ were from tracheal aspirate $(33 \%, n=18)$, rectal swab, $(22 \%, n=12)$, and blood $(24 \%, n=13)$ cultures, while $11(21 \%)$ came from wound $(9 \%, n=5)$, catheter tip ( $4 \%$, $n=2)$, surgical drain $(4 \%, n=2)$, sputum $(2 \%, n=1)$, and urine $(2 \%, n=1)$ cultures (Figure 1B). Antibiotic resistance profiles of $S$. marcescens isolated from the abovementioned different sites showed that all strains were resistant to $\beta$-lactams antibiotics. In addition, colistin (CST) and tigecycline (TGC) non-susceptibility pattern of $S$. marcescens per site of isolation was statistically significant $(p<0.01)$ in several organs (tracheal aspirate, blood, rectal swab, and wound) when compared with amikacin (AMK), gentamicin (GEN), and ciprofloxacin (CIP) antibiotics (Figure 1C).

\section{Antimicrobial Resistance Profile and Genetic Markers for Antibiotic-Resistance and Virulence Patterns}

Serratia marcescens strains showed high-levels of resistance to all $\beta$-lactams (100\%, $n=54)$ (TZP, CAZ, CRO, FEP, ETP, IPM, MEM), including high-levels of intrinsic resistance to $\beta$-lactams (AMP, SAM, CXM, FOX) (100\%, $n=54)$ and colistin (CST) $(96.3 \%, n=52)$. Resistance to tigecycline (TGC) S. marcescens was found in nearly all isolates $(92.6 \% ; n=50)$. However, for the antibiotics classes fluoroquinolones (CIP) $(81.5 \%, n=44)$ and aminoglycosides such as gentamicin (GEN) $(81.5 \%, n=44)$, amikacin (AMK) $(85.2 \%, n=46)$ (Figure 2A), high susceptibility profile was detected. In contrast, MDR was observed in $24.1 \%(n=13)$ of the isolates, and the most common MDR profile was related to $\beta$-lactams-glycylcyclineaminoglycosides-quinolone $(14.8 \%, n=8)$, followed by $\beta$ lactams-glicylcycline-quinolone $(5.6 \%, n=3)$, and ( $\beta$-lactamsglicylcycline-aminoglycosides $3.7 \%, n=2)$.

All 54 tested isolates harbored KPC-carbapenemase (bla $\left.a_{K P C}\right)$ and ESBL $\left(b l a_{T E M}\right)$ genes. The ESBL-encoding genes bla was detected in $14.8 \%(8 / 54)$, and the bla $C T X-M-1$ group in $16.7 \%$ (9/54). However, the bla $a_{S H V}$ variants, bla $I M P, b l a_{O X A-48}$, $b l a_{N D M}, b l a_{V I M}$, and $m c r-1$ genes were not detected. The aac $\left(6^{\prime}\right)-$ Ib-cr variant gene that can induce simultaneous resistance against aminoglycoside and fluoroquinolone was found in 13 (24.1\%) strains. The RND pump efflux encoding genes SdeY and $S d e B$ were identified in all strains while the outer membrane component gene (HasF) was present in 48 (88.9\%). Thus, the coexistence of $S d e \mathrm{Y} / \mathrm{HasF}$ genes and $\mathrm{SdeB} / \mathrm{HasF}$ was observed in 49 (88.9\%) strains (Figure 2B). Finally, with the exception of one strain (Sm40), the virulence-associated genes PigP, FlhD, ShlA, and PhlA were regularly distributed among $S$. marcescens strains, which were detected in $98.2 \%$ of all strains (Figure $2 B$ ).

\section{Resistance Phenotype-Genotype Correlation and Genetic Markers for Virulence Factors}

The correlation between the results of phenotypic and genotypic detection and the presence of virulence genes is shown in Figure 3.
All isolates carried $b l a_{K P C}$ and conferred resistance to all beta-lactam, including carbapenem antibiotics. Furthermore, all detectable bla genes in bla $a_{C T X-M-1} b l a_{O X A-1}$, and bla $a_{T E M}$ group presented ESBL phenotype. Of the 13 isolates with aac(6')Ib-cr gene, $9(69.2 \%)$ were non-susceptible to gentamicin, 7 (53.9\%) to amikacin, and $8(61.5 \%)$ to ciprofloxacin. Among the $49(88.9 \%)$ HasF-positive isolates, 44 (81.5\%) were nonsusceptible to tigecycline.

\section{ERIC-PCR}

The ERIC-PCR results indicated that the majority of the isolates presented a rate of genetic similarity above 85\% (Figure 4). Almost all strains (96.3\%) were grouped into a large cluster named B cluster, sharing $86.4 \%$ of genetic similarity. In addition, the B cluster was separated into two sub-clusters named B1, with 21 isolates, and B2, with 31 isolates, sharing a genetic similarity of $96.1 \%$ and $100 \%$, respectively. Although the cluster B1 presented two subgroups with 4 and 17 isolates, they showed $100 \%$ genetic similarity in each one. Interestingly, two strains ( $S m 38$ and Sm40) were grouped separately within the A cluster and presented $71.4 \%$ of genetic similarity (Figure 4).

\section{DISCUSSION}

Serratia marcescens is a prominent opportunistic pathogen that frequently causes infections in intensive care, surgical and dialysis units (Krishnan et al., 1991; Martineau et al., 2018). In Brazil, there are only few studies on S. marcescens (Ribeiro et al., 2013; Silva et al., 2015). Therefore, we here describe the presence of MDR $S$. marcescens isolates producing KPCcarbapenemase $\left(b l a_{K P C}\right)$ and extended spectrum beta-lactamase (bla $a_{T E M}$, bla $a_{C T X-M-1 \text { group e bla }}$ OXA-1, 4and 30) in the state of Tocantins, Brazil. Tocantins, located southeast of the Northern Region, is the newest state of Brazil and shares borders with six states presenting intensive migration flow.

Serratia marcescens were isolated mainly from male patients with 60 or more years of age, similarly to previous studies that demonstrated advanced age male patients as presenting a higher risk of contracting S. marcescens infections (Ulu-Kilic et al., 2013; Kim et al., 2015; O'Horo et al., 2017). Samples with higher amounts of $S$. marcescens were those from tracheal aspirate, followed by blood, rectal swab, and wounds. Our findings corroborate studies by Kim et al. (2015) and Liou et al. (2014) that reported the respiratory tract as the main route of infection for $S$. marcescens. Other studies have also reported S. marcescens in other sites as bloodstream (Seeyave et al., 2006) and wounds (Us et al., 2017), demonstrating the versatility of these strains in colonizing the host and affecting a wide variety of physiological system.

In addition to the intrinsic resistance to the antibiotics AMP, SAM, CXM, FOX, and CST, we found multidrug-resistant (MDR) S. marcescens isolates to beta-lactam, glycylcycline, and/or aminoglycoside and quinolone group antibiotics. This is in line with other studies that have also reported MDR S. marcescens mainly to beta-lactam, aminoglycoside, and quinolone antibiotics groups (Stock et al., 2003), in hospital 
A

\begin{tabular}{cc}
\hline Characteristics & $\%(\mathbf{n})$ \\
\hline Sex & \\
Male & $68.52(37)$ \\
Female & $31.48(17)$ \\
Age & \\
0-1 day & $12.96(7)$ \\
$18-59$ years & $38.89(21)$ \\
$<60$ years & $48.15(26)$ \\
\hline
\end{tabular}

B

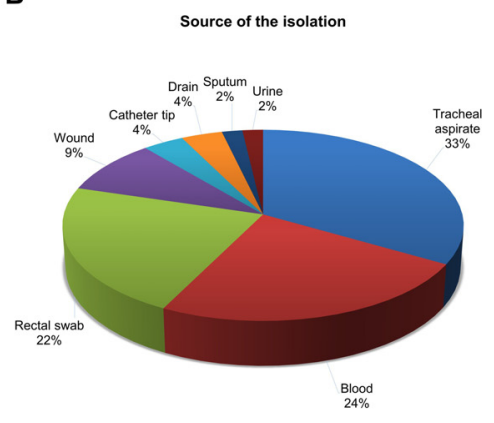

C Antiobiotic non-suceptibility stratified by source of isolation

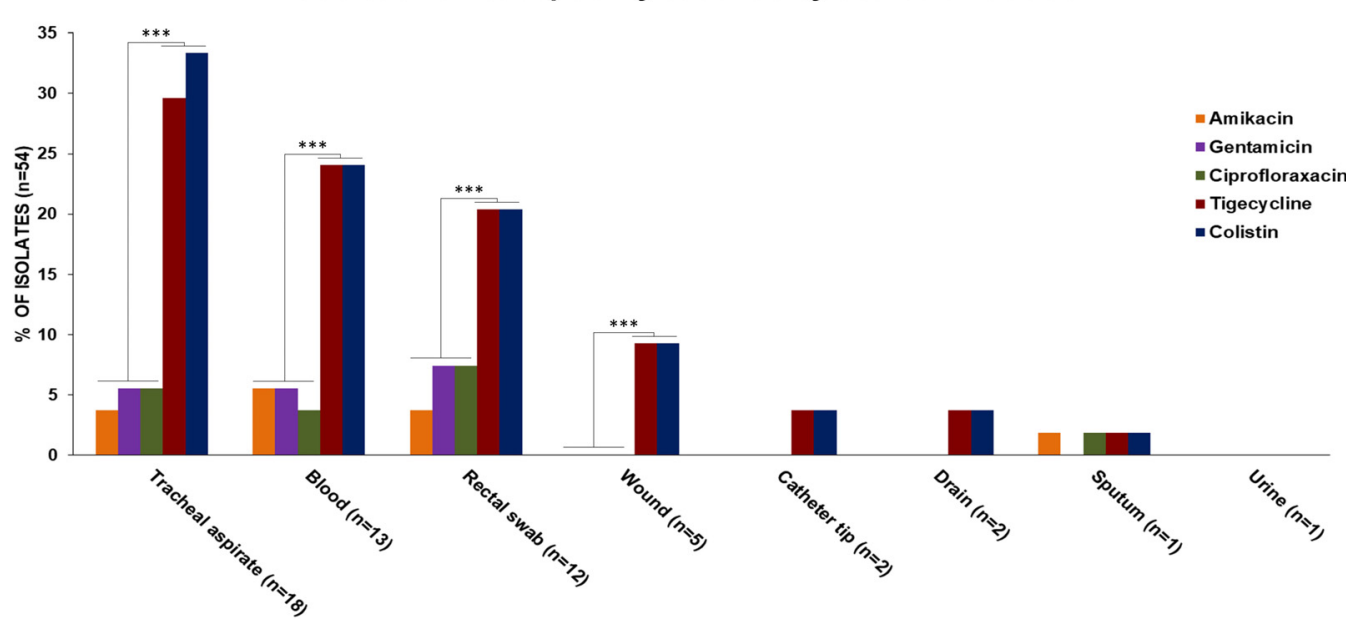

FIGURE 1 | (A) Demographic characteristics of patients. (B) Percentage of S. marcescens per site of isolation. (C) Antibiotic non-susceptibility pattern of S. marcescens per site of isolation. ${ }^{\star \star \star}$ statistical significance, $p$-value $<0.01$.

environment (Merkier et al., 2013), and particularly in critically ill patients and neonatal intensive care units (Maragakis et al., 2008). We also observed a significant resistance to colistin and tigecycline in several colonization sites, as shown by a previous study (Silva et al., 2017).

All the $S$. marcescens strains tested here were resistant to $\beta$-lactams, including carbapenems antibiotics. Resistance to carbapenems used to be uncommon among Serratia species (Stock et al., 2003), but many resistant strains have now emerged throughout the world (Lin et al., 2016). Although few studies have related resistance to carbapenems in S. marcescens in Brazil (Milisavljevic et al., 2004; da Costa Guimarães et al., 2013; Ribeiro et al., 2013), Silva et al. (2015) obtained similar results. They have isolated $S$. marcescens resistant to imipenem, meropenem and ertapenem in samples from different infection sites of ICU patients in another Brazilian locality. Both results are troubling. Infections caused by carbapenem-resistant bacteria often do not respond to conventional treatment (Okoche et al., 2015), as produced carbapenemases hydrolyze not only carbapenems but also penicillins, cephalosporins and monobactams
(Queenan and Bush, 2007). The most common carbapenem resistance of $S$. marcescens in Brazil is due to the production of carbapenamases, especially the KPC-2 type (da Costa Guimarães et al., 2013; Ribeiro et al., 2013), that is encoded by the gene bla $a_{K P C-2}$.

Enterobacteriaceae, such as $S$. marcescens, have the genes bla $a_{T E M-1}$ and $b l a_{S H V-1}$; these genes express classical class A betalactamases, encoded by plasmid that hydrolyze first generation penicillins and cephaloporins (Bush, 2010). We found gene bla $a_{T E M}$ in all isolates while gene bla $a_{S H V v a r i a n t s}$ was not detected. It is noteworthy that even though $S$. marcescens also carries the gene bla $a_{C T X-M}$ (Yu et al., 2003; Kim et al., 2005; Tenover et al., 2013), few of our strains had the gene. Some strains also carried the genes bla $a_{O X A-1}, 4$ and 30 , that have been reported in few studies in Brazil or in other countries, either alone or associated with extended spectrum beta-lactamases genes (ESBL) (bla $a_{T E M}, b l a_{S H V}$ e bla $\left.a_{C T X-M}\right)$ in S. marcescens strains. Although there are discrepancies in frequency rate and in genotyping of ESBL-producing S. marcescens (Cheng et al., 2006), the observed beta-lactam antibiotic resistance may have also been caused by the genes bla $a_{T E M}$, bla $a_{C T X-M}$, and 
A

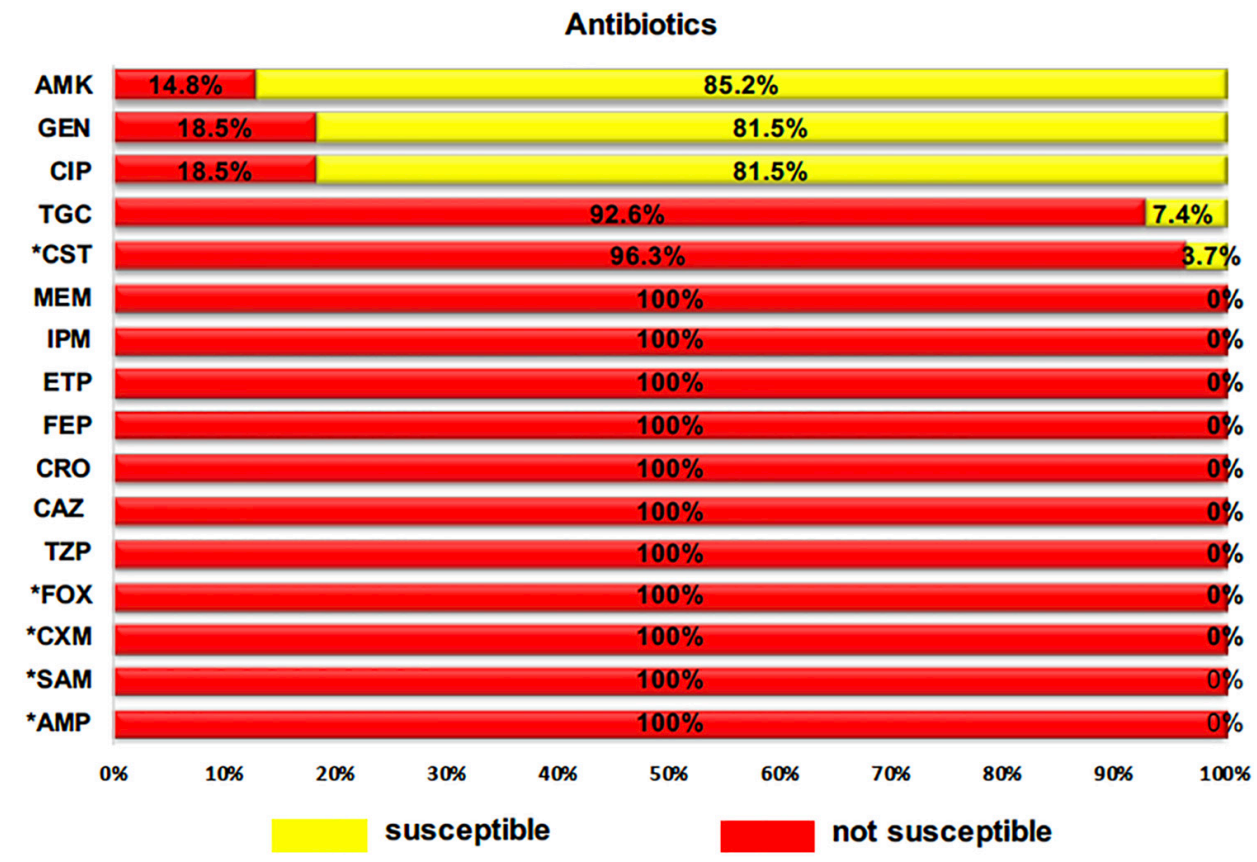

B

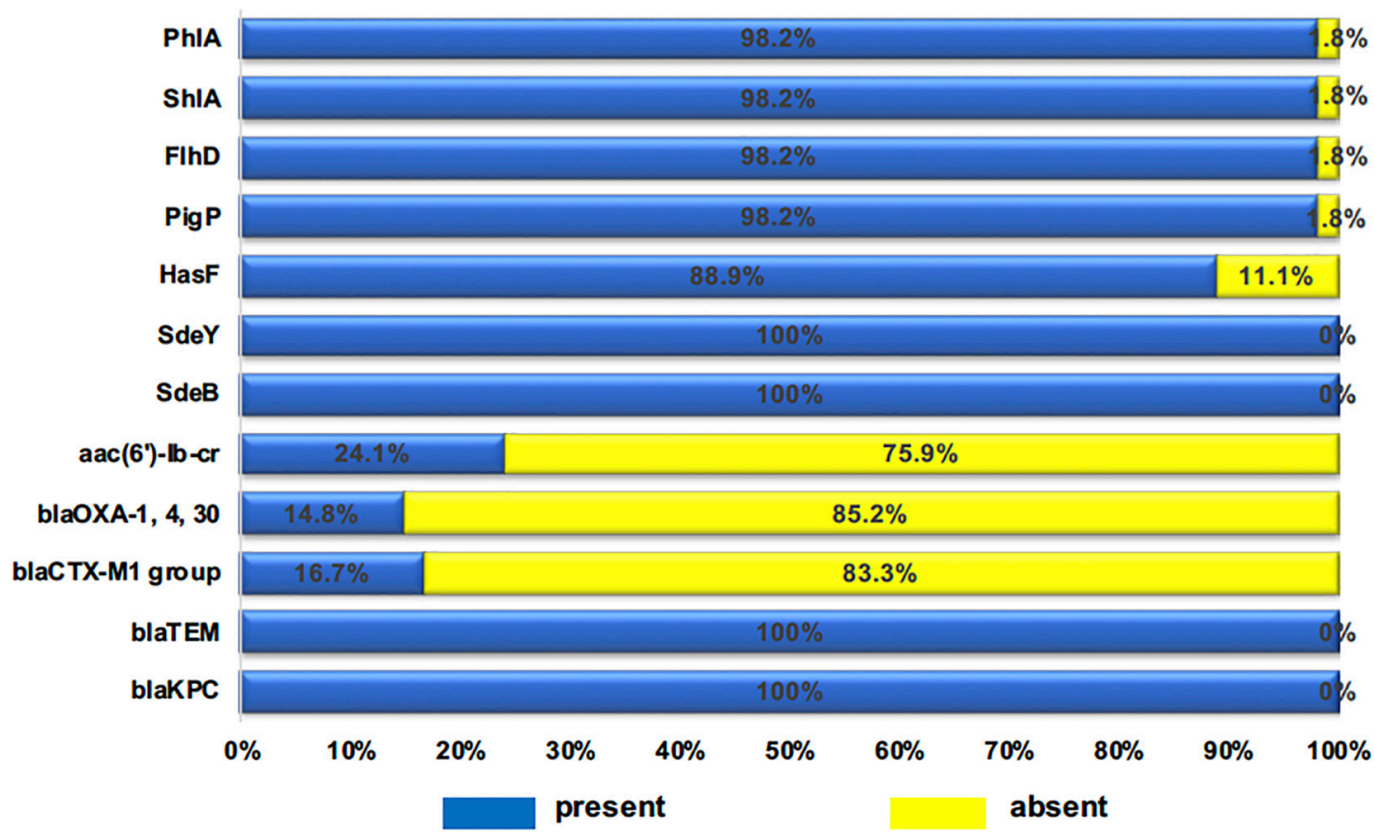

FIGURE 2 | (A) Percentage of clinical isolates not susceptible to 16 antibiotics tested. AMP (ampicillin), SAM (ampicillin-sulbactam), TZP (piperacillin-tazobactam), CXM (cefuroximeaxetil), FOX (cefoxitin), CAZ (ceftazidime), CRO (ceftriaxone), FEP (cefepime), ETP (ertapenem), IPM (imipenem), MEM (meropenem), AMK (amikacin), GEN (gentamicin), CIP (ciprofloxacin), TGC (tigecycline), CST (colistin); * intrinsic resistance to antibiotics. (B) Percentage of genetic markers for resistance and virulence genes. bla KPC $_{\text {, bla }}$ TEM $_{\text {, bla }}$ TX $-M 1_{1}$, aac(6')-lb-cr: resistance genes; SdeB, SdeY, HasF: efflux pump and outer membrane component genes; PigP, FlhD, ShIA, PhlA: virulence genes.

bla $a_{\mathrm{OXA}}$, since the production of broad-spectrum beta-lactamases enzymes (TEM-1, TEM-2, SHV-1, OXA-1) generate resistant to ampicillin, ticarcillin, piperacillin, piperacillin/tazobactam and cephalosporin antibiotics, and the enzymes CTX-M have hydrolytic activity against cefotaxime (Levy and Marshall, 2004; Sugumar et al., 2014). 


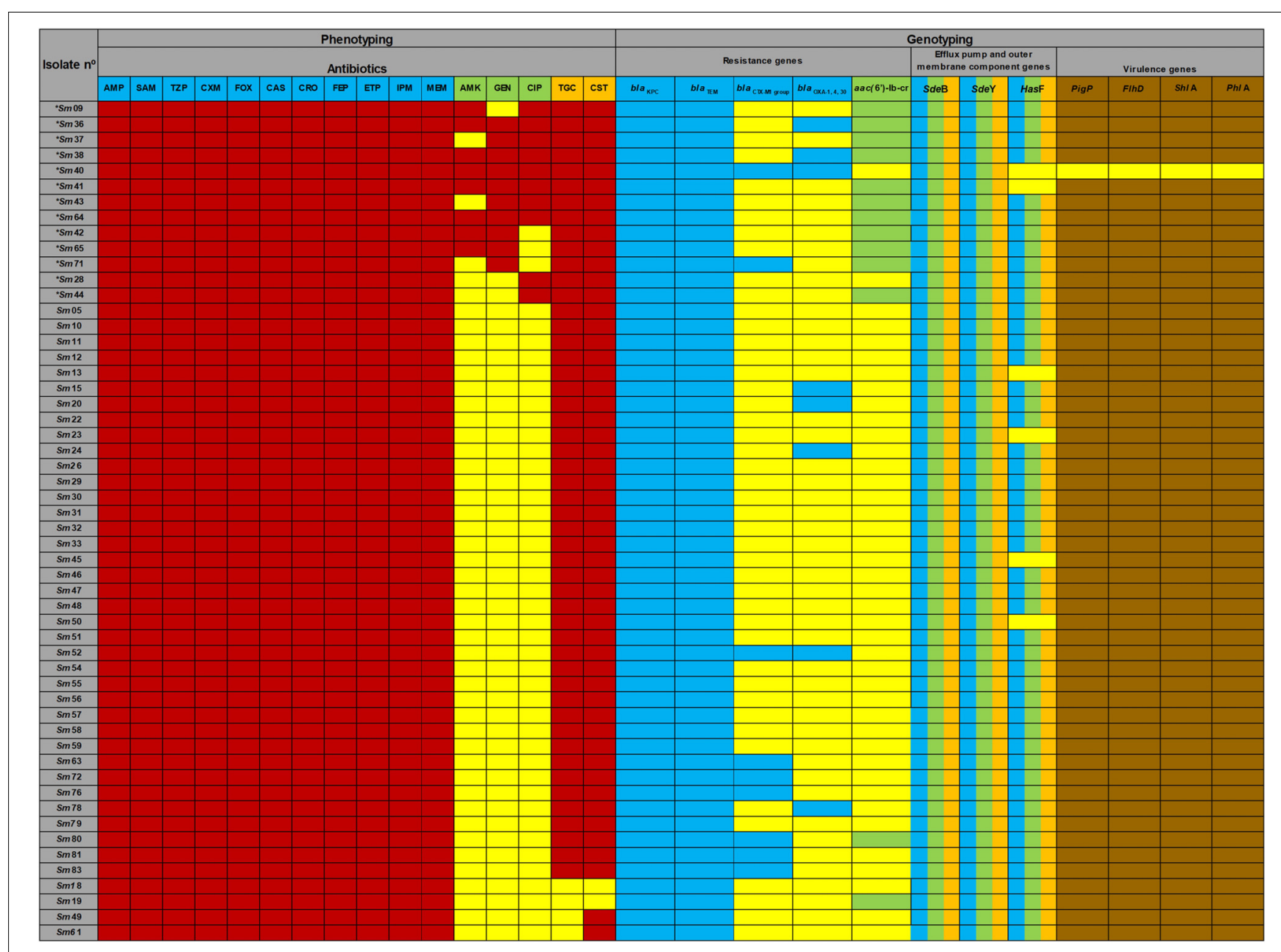

FIGURE 3 | Phenotyping and genotyping of Serratia marcescens isolates. Sm represents Serratia marcescens and numbers represent identifications of strains. ${ }^{\star}$ Sm is classified as multidrug resistant (MDR) strains. AMP (ampicillin), SAM (ampicillin-sulbactam), TZP (piperacillin-tazobactam), CXM (cefuroximeaxetil), FOX (cefoxitin), CAZ (ceftazidime), CRO (ceftriaxone), FEP (cefepime), ETP (ertapenem), IPM (imipenem), MEM (meropenem), AMK (amikacin), GEN (gentamicin), CIP (ciprofloxacin). Serratia marcescens are intrinsically resistant to TGC (tigecycline) and CST (colistin). AMP, SAM, CXM, FOX, and CST antibiotics were not included in the MDR

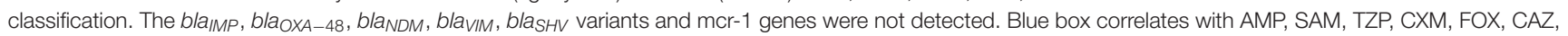
CRO, FEP, ETP, IPM, MEM. Green box correlate with AMK, GEN, CIP. Multicolored box (HasF) correlates with CIP and TGC. Brown box shows number of S. marcescens caring virulence genes.

In our study, most strains of S. marcescens were only sensitive to aminoglycosides (gentamicin and amikacin) and fluoroquinolone (ciprofloxacin). Aminoglycosides are the oldest antibiotics that have been used less frequently in the last years, thus possibly preserving activity against some resistant bacteria that cause difficult to cure infections (Falagas et al., 2008; Gad et al., 2011). The observed low resistance to ciprofloxacin $(18.18 \%)$ is in agreement with the results obtained by Sheng et al. (2002) who observed $20-30 \%$ resistance to quinolone in S. marcescens isolates. However, it is important to consider that $S$. marcescens is highly adaptable, so rates of resistance to fluoroquinolones diverge considerably among institutions (Young et al., 1980; Mahlen, 2011; Sader et al., 2014), including within Brazilian ones.

Resistance to fluoroquinolones may be caused by alterations in the target enzymes DNA gyrase and topoisomerase IV, and by acquisition of the transferable plasmid-mediated quinolone resistance (PMQR) determinants qnr, qepA, aac(6')-Ib-cr, and oqxAB (Veldman et al., 2011; Poirel et al., 2012; Moradigaravand et al., 2016). The gene aac (6 $\left.6^{\prime}\right)$-Ib-cr, a variant gene of the aminoglycoside acetyltransferase, was also present in most of strains that presented fluoroquinolone and/or aminoglycoside resistance. This finding is consistent with others studies that have shown that $a a c\left(6^{\prime}\right)$-Ib-cr may be associated with antibacterial resistance against fluoroquinolone and aminoglycoside (Kim et al., 2009, 2011) antibiotics.

Three RND-type efflux have been reported in S. marcescens, namely SdeAB (Kumar and Worobec, 2005a), SdeCDE (Kumar and Worobec, 2005a; Begic and Worobec, 2008), and SdeXY (Chen et al., 2003). SdeAB and SdeXY interact with HasF (an outer membrane component, TolC homolog gene) contributing to resistance against a wide variety of antimicrobial agents 


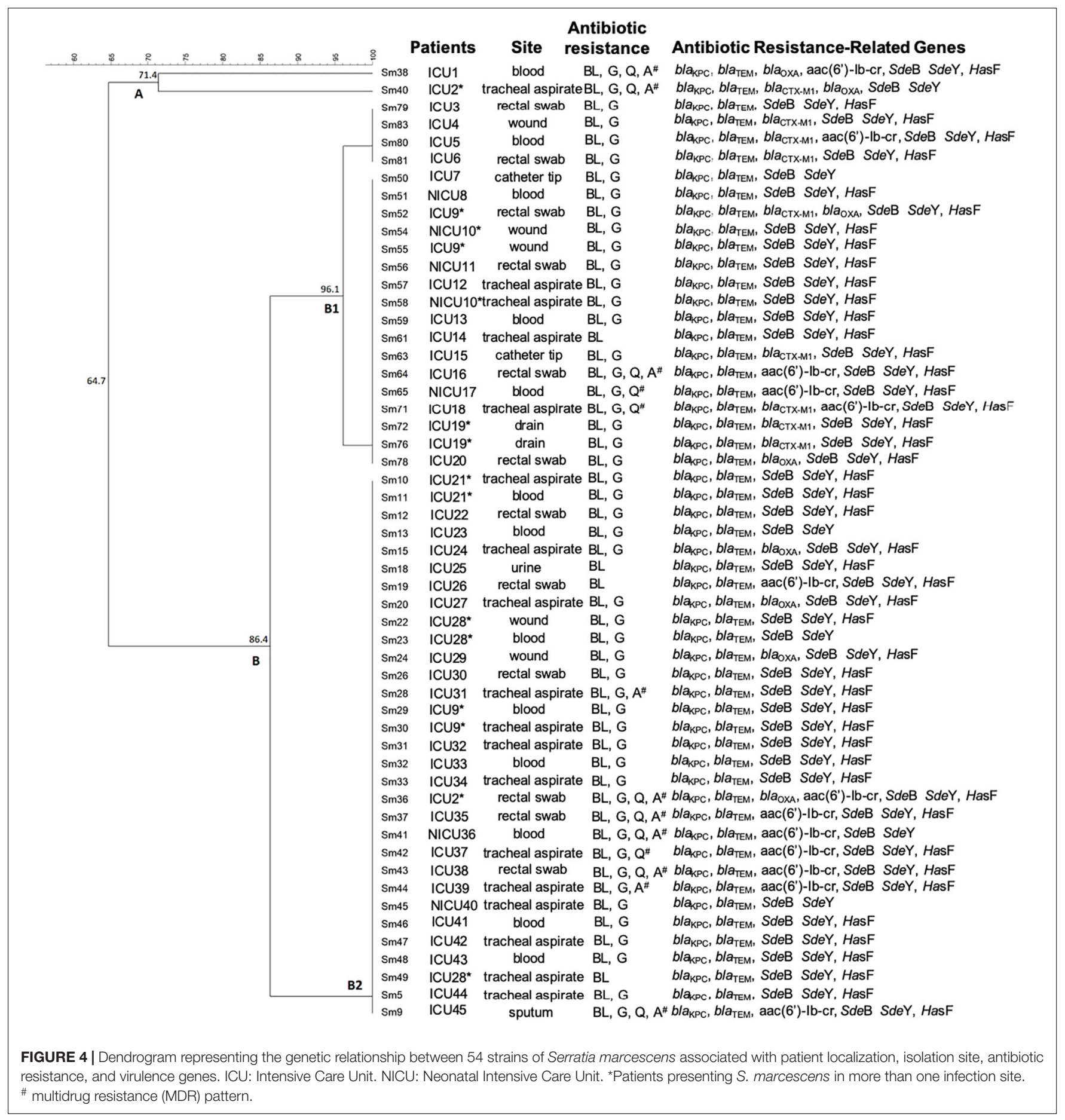

(Begic and Worobec, 2008; Hornsey et al., 2010). Although we did not analyze the genes $S d e A$ e $S d e X$, the genes $S d e B$ and SdeX were present in all strains and the gene Has $\mathrm{F}$ was also found in most strains. Drug extrusion by efflux pumps as SdeAB-Has F comprises one of the main mechanisms for fluoroquinolones antibiotic resistance (Dalvi and Worobec, 2012). Additionally, Hornsey et al. (2010) has shown the intrinsic activity of the SdeXY-HasF efflux pump is responsible for the lower susceptibility to ciprofloxacin. Thus, in addition to the presence of the genes $\operatorname{acc}\left(6^{\prime}\right)$-Ib-cr [associated with plasmid-mediated quinolone resistance (PMQR)], the genes $S d e \mathrm{~B}, \mathrm{SdeY}$, and $\mathrm{Has} \mathrm{F}$ that encode RND-type efflux pump may have contributed to the observed ciprofloxacin resistance.

Our data shows high prevalence of tigecycline-resistant S. marcescens strains and SdeY and Has $\mathrm{F}$ genes. The reduced sensitivity of $S$. marcescens to tigecycline may be related to the 
up-regulation of the SdeXY-HasF efflux pump (Hornsey et al., 2010). Although the gene SdeX was not analyzed, our findings strongly suggest that these genes may be responsible for the high tigecycline resistance.

Many bacteria produce virulence factors as hydrolytic enzymes and toxins that enable host invasion, bacterial proliferation and inhibit host defense mechanisms, sometimes resulting in host death (Aggarwal et al., 2017). S. marcescens strains were also evaluated for the presence of toxin genes ShlA and phlA, and all but the Sm40 strain carried these genes. Our findings are in agreement with other studies that reported the presence these genes in $S$. marcescens (strain SEN) (Aggarwal et al., 2017). FlhDC has been proposed as a regulator controlling flagellum biogenesis, biofilm formation, cell septation and expression of virulence factors during swarming (Givskov et al., 1995; Fraser and Hughes, 1999; Chilcott and Hughes, 2000; Lin et al., 2010). In our study, the presence of FlhC was not analyzed but the gene FlhD was present in almost all isolates. S. marcescens produces biosurfactant serrawettin and red pigment prodigiosin used in surfaces colonization (Hejazi and Falkiner, 1997). PigP is a positive regulator of prodigiosin production that regulates swarming and hemolysis through serratamolide production (Fineran et al., 2005; Shanks et al., 2013). In our study, PigP gene was found in almost all isolates (98.15\%). Overall, our results suggest that the combination of these virulence genes could have contributed to the pathogenicity of S. marcescens strains.

The dendrogram based on ERIC-PCR fingerprint analysis demonstrated that the vast majority of isolates are closely related, sharing a genetic similarity of $86.4 \%$ (except for two strains). In addition, many isolates showed $100 \%$ similarity to each other. A study conducted by Ferreira-Firmo et al. (2019) evaluated nine S. marcescens from different clinical sources and three hospitals in Northeast Brazil showed a greater genetic diversity among the studied strains. Lin et al. (2016) studied 83 carbapenem-resistant S. marcescens isolates recovered from Zhejiang Provincial 501 People's Hospital, China, from which they found 63 blaKPC-2 positive strains sharing nine different profiles. Our results demonstrate the predominance of few genetic profiles grouped together, with similarity above $85 \%$, indicating that, although bacteria have been isolated from different patients and devices, the circulating $S$. marcescens in this hospital is highly genetically related.

Our study has some limitations worth noting. There was a high number of $S$. marcescens isolated from rectal swabs and tracheal aspirate, and both cultures are recommended for surveillance in ICU and NICU patients. However, microbiological reports sent to LACEN were not clear regarding how many of these samples were analyzed for both clinical and surveillance purposes. This study was further limited by the duration of the research, which was relatively short (2014-2015), and by conventional phenotypic and genotypic techniques, that have their own particular strengths and limitations in detecting MDR strains. Nonetheless, we intend to extend the analysis period of $S$. marcescens isolates, and whole genome sequencing to type relevant MDR strains must be performed. We expect that this study broadens our understanding on epidemiology, antibiotic resistance, and putative virulence factors of these strains, and provides relevant information for the prevention and management of S. marcescens infections.

In conclusion, S. marcescens represents a problem for public health (Kurz et al., 2003) and the resistance pattern exhibited by clinical isolates along with the transmission to other clones show the importance of researching factors associated with the increase in frequency and/or emergence of infections caused by $S$. marcescens in Brazilian hospitals. The occurrence of antibiotic-resistant bacteria considerably varies according to country, region and susceptible population, and the mitigation of this problem in ICUs is especially associated with actions to control the spreading of such drugresistant bacteria (Ko et al., 2002; Hou et al., 2015). Thus, it is crucial to eliminate sources of resistance development and associated reservoirs as well as to overtake standardized sanitation and enforce mandatory notification to gather important data for continuous risk assessment evaluation and effective decision making to control these species in hospital environments.

\section{DATA AVAILABILITY STATEMENT}

The datasets generated for this study can be found in the GenBank database. Genes and their respective accession numbers: blaCTX - MK576103; blaKPC - MK576104; blaOXA MK576105; blaTEM - MK576106; SdeB - MN583232; SdeY MN583233; HasF - MN583234; aac(6')-Ib-cr - MN583235; FlhD - MN583236; PigP - MN583237; ShlA - MN583238; PhlA MN583239). Access to genetic heritage was approved by the National System for the Management of Genetic Heritage (SisGen $\mathrm{n}^{\circ}$ AFF27ED).

\section{ETHICS STATEMENT}

The studies involving human participants were reviewed and approved by the Committee of Ethics in Human Research of the Federal University of São Carlos (no. 1.088.936). In this work, all Serratia marcescens and the anonymous archival data related patient age, gender, and sample type were obtained from the Central Laboratory of Public Health of Tocantins (LACEN/TO, data's owner). Permission to conduct the present study was obtained from the Health Department of the State of Tocantins (Secretaria da Saúde do Estado do Tocantins - SESAU) and LACEN/TO. Patient consent was not required, since the data presented in this study do not relate to any specific person or persons. Written informed consent from the participants' legal guardian/next of kin was not required to participate in this study in accordance with the national legislation and the institutional requirements. 


\section{AUTHOR CONTRIBUTIONS}

RF, GR, MD, MO-S, MB, and M-CP performed the experiments. FG and EL aided with statistical analysis. EC aided with the sequencing analysis and the sequence submission to the NCBI platform. M-CP conceived and supervised the study. M-CP, AC, $\mathrm{IM}$, and AP-S wrote the manuscript and analyzed the data. MO-S performed ERIC-PCR.

\section{FUNDING}

This work was supported by the Fundação de Amparo a Pesquisa do Estado de São Paulo (FAPESP grants 2020/056996 to M-CP and FAPESP grant 2013/22581-5 to AP-S) and Conselho Nacional de Desenvolvimento Científico e Tecnológico (CNPq, grant 2013/485873 to M-CP). This study was partially financed by the Fundação de Amparo á Pesquisa do Estado de São Paulo-Brazil (FAPESP) as a fellowship to MD (FAPESP fellowship 2018/24213-7), and by

\section{REFERENCES}

Aggarwal, C., Paul, S., Tripathi, V., Paul, B., and Khan, M. A. (2017). Characterization of putative virulence factors of Serratia marcescens strain SEN for pathogenesis in Spodoptera litura. J. Invertebr. Pathol. 143, 115-123. doi: 10.1016/j.jip.2016.12.004

Anderson, K. F., Lonsway, D. R., Rasheed, J. K., Biddle, J., Jensen, B., McDougal, L. K., et al. (2007). Evaluation of methods to identify the Klebsiella pneumoniae Carbapenemase in Enterobacteriaceae. J. Clin. Microbiol. 45, 2723-2725. doi: 10.1128/JCM.00015-07

Begic, S., and Worobec, E. A. (2008). Characterization of the Serratia marcescens SdeCDE multidrug efflux pump studied via gene knockout mutagenesis. Can. J. Microbiol. 54, 411-416. doi: 10.1139/w08-019

Bush, K. (2010). The coming of age of antibiotics: discovery and therapeutic value. Ann. N. Y. Acad. Sci. 1213, 1-4. doi: 10.1111/j.1749-6632.2010.05872.x

Cao, X., Xu, X., Zhang, Z., Shen, H., Chen, J., and Zhang, K. (2014). Molecular characterization of clinical multidrug-resistant Klebsiella pneumoniae isolates. Ann. Clin. Microbiol. Antimicrob. 13:16. doi: 10.1186/1476-0711-13-16

Chen, J., Kuroda, T., Huda, M. N., Mizushima, T., and Tsuchiya, T. (2003). An RND-type multidrug efflux pump SdeXY from Serratia marcescens. J. Antimicrob. Chemother. 52, 176-179. doi: 10.1093/jac/dkg308

Cheng, K., Chuang, Y., Wu, L., Huang, G., and Yu, W. (2006). Clinical experiences of the infections caused by extended-spectrum beta-lactamase-producing Serratia marcescens at a medical center in Taiwan. Jpn. J. Infect. Dis. 59, 147-152.

Chilcott, G. S., and Hughes, K. T. (2000). Coupling of flagellar gene expression to flagellar assembly in Salmonella enterica serovar typhimurium and Escherichia coli. Microbiol. Mol. Biol. Rev. 64, 694-708. doi: 10.1128/mmbr.64.4.694-708. 2000

CLSI (2019). Performance Standards for Antimicrobial Susceptibility Testing. CLSI Supplement M100, 29th Edn. Wayne, PA: Clinical and Laboratory Standards Institute.

Cristina, M. L., Sartini, M., and Spagnolo, A. M. (2019). Serratia marcescens Infections in Neonatal Intensive Care Units (NICUs). Int. J. Environ. Res. Public Health 16:E610. doi: 10.3390/ijerph16040610

da Costa Guimarães, A. C., Almeida, A. C. S., Nicoletti, A. G., Vilela, M. A., Gales, A. C., and Morais, M. M. C. (2013). Clonal spread of carbapenem-resistant Serratia marcescens isolates sharing an IncK plasmid containing blaKPC2. Int. J. Antimicrob. Agents 42, 369-370. doi: 10.1016/j.ijantimicag.2013. 05.017

Dallenne, C., Da Costa, A., Decre, D., Favier, C., and Arlet, G. (2010). Development of a set of multiplex PCR assays for the detection of genes encoding important the Coordenação de Aperfeiçoamento de Pessoal de Nível Superior - Brazil (CAPES) - Finance Code 001 as a fellowship to GR, FG, and EC.

\section{ACKNOWLEDGMENTS}

The authors thank the Laboratório Central de Saúde Pública do Tocantins, Palmas, TO, Brazil (LACEN-TO) who kindly provided the $S$. marcescens strains, and to Secretaria de Saúde do Estado do Tocantins (SESAU-TO) for facilitating the development of project.

\section{SUPPLEMENTARY MATERIAL}

The Supplementary Material for this article can be found online at: https://www.frontiersin.org/articles/10.3389/fmicb. 2020.00956/full\#supplementary-material

B-lactamases in Enterobacteriaceae. J. Antimicrob. Chemother. 65, 490-495. doi: $10.1093 / \mathrm{jac} / \mathrm{dkp} 498$

Dalvi, S. D., and Worobec, E. A. (2012). Gene expression analysis of the SdeAB multidrug efflux pump in antibiotic-resistant clinical isolates of Serratia marcescens. Indian J. Med. Microbiol. 30, 302-307. doi: 10.4103/0255-0857. 99491

David, M. D., Weller, T. M., Lambert, P., and Fraise, A. P. (2006). An outbreak of Serratia marcescens on the neonatal unit: a tale of two clones. J. Hosp. Infect. 63, 27-33. doi: 10.1016/j.jhin.2005.11.006

Dawczynski, K., Proquitté, H., Roedel, J., Edel, B., Pfeifer, Y., Hoyer, H., et al. (2016). Intensified colonisation screening according to the recommendations of the German Commission for Hospital Hygiene and Infectious Diseases Prevention (KRINKO): identification and containment of a Serratia marcescens outbreak in the neonatal intensive care unit, Jena, Germany, 2013-2014. Infection 44, 739-746. doi: 10.1007/s15010-016-0922-y

Doyle, D., Peirano, G., Lascols, C., Lloyd, T., Church, D. L., and Pitout, J. D. (2012). Laboratory detection of Enterobacteriaceae that produce carbapenemases. J. Clin. Microbiol. 50, 3877-3880. doi: 10.1128/JCM.02117-12

Enciso-Moreno, J. A., Pernas-Buitrón, N., Ortiz-Herrera, M., and Coria-Jiménez, R. (2004). Identification of Serratia marcescens populations of nosocomial origin by RAPD-PCR. Arch. Med. Res. 35, 12-17. doi: 10.1016/j.arcmed.2003. 07.005

EUCAST (2018). The European Committee on Antimicrobial Susceptibility Testing . 2018. Breakpoint tables for Interpretation of MICs and Zone Diameters. Available online at: https://www.eucast.org/fileadmin/src/media/ PDFs/EUCAST_files/Breakpoint_tables/v_8.1_Breakpoint_Tables.pdf

Falagas, M. E., Grammatikos, A. P., and Michalopoulos, A. (2008). Potential of oldgeneration antibiotics to address current need for new antibiotics. Expert Rev. Anti Infect. Ther. 6, 593-600. doi: 10.1586/14787210.6.5.593

Ferreira, R. L., Silva, B. C. M., Rezende, G. S., Nakamura-Silva, R., Pitondo-Silva, A. Campanini, E. B., et al. (2019). High prevalence of multidrug-resistant Klebsiella pneumoniae harboring several virulence and $\beta$-Lactamase encoding genes in a Brazilian intensive care unit. Front. Microbiol. 9:3198. doi: 10.3389/fmicb.2018. 03198

Ferreira-Firmo, E., Beltrão, E. M. B., da Silva, F. R. F., Alves, L. C., Brayner, F. A., Veras, D. L., et al. (2019). Association of blaNDM-1 with blaKPC-2 and aminoglycoside-modifying enzymes genes among Klebsiella pneumoniae, Proteus mirabilis and Serratia marcescens clinical isolates in Brazil. J. Glob. Antimicrob. Resist. doi: 10.1016/j.jgar.2019.08.026 [Epub ahead of print].

Fineran, P. C., Slater, H., Everson, L., Hughes, K., and Salmond, G. P. (2005). Biosynthesis of tripyrrole and beta-lactam secondary metabolites in Serratia: integration of quorum sensing with multiple new regulatory 
components in the control of prodigiosin and carbapenem antibiotic production. Mol. Microbiol. 56, 1495-1517. doi: 10.1111/j.1365-2958.2005.04 660.x

Fraser, G. M., and Hughes, C. (1999). Swarming motility. Curr. Opin. Microbiol. 2, 630-635.

Gad, G. F., Heba, A., Mohamed, and Hossam, M. A. (2011). aminoglycoside resistance rates, phenotypes, and mechanisms of Gram-negative bacteria from infected patients in upper Egypt. PLoS One 6:e17224. doi: 10.1371/journal.pone. 0017224

Gastmeier, P. (2014). Serratia marcescens: an outbreak experience. Front. Microbiol. 5:81. doi: 10.3389/fmicb.2014.00081

Gastmeier, P., Loui, A., Stamm-Balderjahn, S., Hansen, S., Zuschneid, I., Sohr, D., et al. (2007). Outbreaks in neonatal intensive care units-they are not like others. Am. J. Infect. Control 35, 172-176. doi: 10.1016/j.ajic.2006.07.007

Ghaith, D. M., Zafer, M. M., Ismail, D. K., Al-Agamy, M. H., Bohol, M. F. F., Al-Qahtani, A., et al. (2018). First reported nosocomial outbreak of Serratia marcescens harboring bla IMP-4 and bla VIM-2 in a neonatal intensive care unit in Cairo, Egypt. Infect. Drug Resist. 11, 2211-2217. doi: 10.2147/IDR.S174869

Givskov, M., Eberl, L., Christiansen, G., Benedik, M. J., and Molin, S. (1995). Induction of phospholipase- and flagellar synthesis in Serratia liquefaciens is controlled by expression of the flagellar master operon flhD. Mol. Microbiol. 15, 445-454. doi: 10.1111/j.1365-2958.1995.tb02258.x

Hall, T. A. (1999). BioEdit: a user-friendly biological sequence alignment editor and analysis program for Windows 95/98/NT. Nucleic Acids Symp. Ser. 41, 95-98.

Hejazi, A., and Falkiner, F. R. (1997). Serratia marcescens. J. Med. Microbiol. 46, 903-912.

Herra, C., and Falkiner, F. R. (2018). Serratia marcescens. In: Antimicrobe Microbes. Available online at: http://www.antimicrobe.org/b26.asp (accessed June 8, 2019).

Hornsey, M., Ellington, M. J., Doumith, M., Hudson, S., Livermore, D. M., and Woodford, N. (2010). Tigecycline resistance in Serratia marcescens associated with up-regulation of the SdeXY-HasF efflux system also active against ciprofloxacin and cefpirome. J. Antimicrob. Chemother. 65, 479-482. doi: 10. 1093/jac/dkp475

Hou, X. H., Song, X. Y., Ma, X. B., Zhang, S. Y., and Zhang, J. Q. (2015). Molecular characterization of multidrug-resistant Klebsiella pneumoniae isolates. Braz. J. Microbiol. 46, 759-768. doi: 10.1590/S1517-838246320140138

Jeon, J., Lee, J., Lee, J., Park, K., Karim, A., Lee, C., et al. (2015). Structural basis for carbapenem-hydrolyzing mechanisms of carbapenemases conferring antibiotic resistance. Int. J. Mol. Sci. 16, 9654-9692. doi: 10.3390/ijms16059654

Kim, E. S., Jeong, J. Y., Jun, J. B., Choi, S. H., Lee, S. O., Kim, M. N., et al. (2009). Prevalence of aac(6')-Ib-cr encoding a ciprofloxacin-modifying enzyme among Enterobacteriaceae blood isolates in Korea. Antimicrob. Agents Chemother. 53, 2643-2645. doi: 10.1128/AAC.01534-08

Kim, J., Lim, Y.-M., Jeong, Y.-S., and Seol, S.-Y. (2005). Occurrence of CTX-M3, CTX-M-15, CTX-M-14, and CTX-M-9 Extended-Spectrum -Lactamases in Enterobacteriaceae Clinical Isolates in Korea. Antimicrob. Agents Chemother. 49, 1572-1575. doi: 10.1128/AAC.49.4.1572-1575.2005

Kim, S. B., Jeon, Y. D., Kim, J. H., Kim, J. K., Ann, H. W., Choi, H., et al. (2015). Risk factors for mortality in patients with Serratia marcescens bacteremia. Yonsei Med. J. 56:348. doi: 10.3349/ymj.2015.56.2.348

Kim, Y. T., Jang, J. H., Kim, H. C., Kim, H., Lee, K. R., Park, K. S., et al. (2011). Identification of strain harboring both aac(6')-Ib and aac(6')-Ib-cr variant simultaneously in Escherichia coli and Klebsiella pneumoniae. BMB Rep. 4, 262-266. doi: 10.5483/BMBRep.2011.44.4.262

Ko, W. C., Paterson, D. L., Sagnimeni, A. J., Hansen, D. S., Von Gottberg, A., Mohapatra, S., et al. (2002). Community-acquired Klebsiella pneumoniae bacteremia: global differences in clinical patterns. Emerg. Infect Dis. 8, 160-166. doi: 10.3201/eid0802.010025

Krishnan, P. U., Pereira, B., and Macaden, R. (1991). Epidemiological study of an outbreak of Serratia marcescens in a haemodialysis unit. J. Hosp. Infect. 18, 57-61. doi: 10.1016/0195-6701(91)90093-n

Kumar, A., and Worobec, E. A. (2005a). Cloning, sequencing, and characterization of the SdeAB multidrug efflux pump of Serratia marcescens. Antimicrob Agents Chemother. 49, 1495-1501. doi: 10.1128/AAC.49.4.1495-1501.2005

Kumar, A., and Worobec, E. A. (2005b). HasF, a TolC-homolog of Serratia marcescens, is involved in energy-dependent efflux. Can. J. Microbiol. 51, 497-500. doi: 10.1139/w05-029
Kurz, C. L., Chauvet, S., Andrès, E., Aurouze, M., Vallet, I., Michel, G. P., et al. (2003). Virulence factors of the human opportunistic pathogen Serratia marcescens identified by in vivo screening. EMBO J. 22, 1451-1460. doi: 10 . 1093/emboj/cdg159

Levy, S. B., and Marshall, B. (2004). Antibacterial resistance worldwide: causes, challenges and responses. Nat. Med. 10, S122-S129. doi: 10.1038/nm1145

Li, H., and Li, J. B. (2005). Detection of five novel CTX-M-type extended spectrum beta-lactamases with one to three CTX-M-14 point mutations in isolates from Hefei, Anhui province, China. J. Clin. Microbiol. 43, 4301-4302. doi: 10.1128/ JCM.43.8.4301-4302.2005

Lin, C. S., Horng, J. T., Yang, C. H., Tsai, Y. H., Su, L. H., Wei, C. F., et al. (2010). RssAB-FlhDC-ShlBA as a major pathogenesis pathway in Serratia marcescens. Infect. Immun. 78, 4870-4881. doi: 10.1128/IAI.00661-10

Lin, X., Hu, Q., Zhang, R., Hu, Y., Xu, X., and Lv, H. (2016). Emergence of Serratia marcescens isolates possessing carbapenem-hydrolysing B-lactamase KPC-2 from China. J. Hosp. Infect. 94, 65-67. doi: 10.1016/j.jhin.2016.04.006

Liou, B. H., Duh, R. W., Lin, Y. T., Lauderdale, T. L., and Fung, C. P. (2014). Taiwan surveillance of antimicrobial resistance (TSAR) hospitals. J. Microbiol. Immunol. Infect. 47, 387-393. doi: 10.1016/j.jmii.2013.04.003

Liu, Y. Y., Wang, Y., Walsh, T. R., Yi, L. X., Zhang, R., Spencer, J., et al. (2015). Emergence of plasmid mediated colistin resistance mechanism MCR-1 in animals and human beings in China: a microbiological and molecular biological study. Lancet Infect. 16, 161-168. doi: 10.1016/S1473-3099(15)00424-7

Magiorakos, A.-P., Srinivasan, A., Carey, R. B., Carmeli, Y., Falagas, M. E., Giske, C. G., et al. (2012). Multidrug-resistant, extensively drug-resistant and pandrug-resistant bacteria: an international expert proposal for interim standard definitions for acquired resistance. Clin. Microbiol. Infect. 18, 268-281. doi: 10.1111/j.1469-0691.2011.03570.x

Mahlen, S. D. (2011). Serratia infections: from military experiments to current practice. Clin. Microbiol. Rev. 24, 755-791. doi: 10.1128/CMR.00017-11

Maragakis, L. L., Winkler, A., Tucker, M. G., Cosgrove, S. E., Ross, T., Lawson, E., et al. (2008). Outbreak of multidrug-resistant Serratia marcescens infection in a neonatal intensive care unit. Infect. Control Hosp. Epidemiol. 29, 418-423. doi: $10.1086 / 587969$

Marschall, J., Tibbetts, R. J., Dunne, W. M., Frye, J. G., Fraser, V. J., and Warren, D. K. (2009). Presence of the KPC carbapenemase gene in Enterobacteriaceae causing bacteremia and its correlation with in vitro carbapenem susceptibility. J. Clin. Microbiol. 47, 239-241. doi: 10.1128/JCM.02123-08

Martineau, C., Li, X., Lalancette, C., Perreault, T., Fournier, E., Tremblay, J., et al. (2018). Serratia marcescens outbreak in a neonatal intensive care unit: new insights from next-generation sequencing applications. J. Clin. Microbiol. 56:e0235-18. doi: 10.1128/JCM.00235-18

Martins, A. F., Zavascki, A. P., Gaspareto, P. B., and Barth, A. L. (2007). Dissemination of Pseudomonas aeruginosa producing SPM-1-like and IMP1-like metallo-beta-lactamases in hospitals from southern Brazil. Infection 35, 457-460. doi: 10.1007/s15010-007-6289-3

Merkier, A. K., Rodríguez, C., Togneri, A., Brengi, S., Osuna, C., and Pichel, M. (2013). Outbreak of a cluster with epidemic behavior due to Serratia marcescens after colistin administration in a hospital setting. J. Clin. Microbiol. 51, 2295-2302. doi: 10.1128/JCM.03280-12

Milisavljevic, V., Wu, F., Larson, E., Rubenstein, D., Ross, B., Drusin, L. M., et al. (2004). Molecular epidemiology of Serratia marcescens outbreaks in two neonatal intensive care units. Infect. Control Hosp. Epidemiol. 25, 719-721. doi: $10.1086 / 502466$

Miriagou, V., Cornaglia, G., Edelstein, M., Galani, I., Giske, C. G., Gniadkowski, M., et al. (2010). Acquired carbapenemases in Gram-negative bacterial pathogens: detection and surveillance issue. Clin. Microbiol. Infect. 16, 112-122. doi: 10.1111/j.1469-0691.2009.03116.x

Mitra, S., Mukherjee, S., Naha, S., Chattopadhyay, P., Dutta, S., and Basu, S. (2019). Evaluation of co-transfer of plasmid-mediated fluoroquinolone resistance genes and bla NDM gene in Enterobacteriaceae causing neonatal septicaemia. Antimicrob. Resist. Infect. Control 8:46. doi: 10.1186/s13756-019-0477-7

Montagnani, C., Cocchi, P., and Lega, L. (2015). Serratia marcescens outbreak in a neonatal intensive care unit: crucial role of implementing hand hygiene among external consultants. BMC Infect. Dis. 15:11. doi: 10.1186/s12879-0140734-6

Moradigaravand, D., Boinett, C. J., Martin, V., Peacock, S. J., and Parkhill, J. (2016). Recent independent emergence of multiple multidrug-resistant Serratia 
marcescens clones within the United Kingdom and Ireland. Genome Res. 26, 1101-1109. doi: 10.1101/gr.205245.116.Freely

Mostatabi, N., Farshad, S., and Ranjbar, R. (2013). Molecular evaluations of extended spectrum $\beta$-lactamase producing strains of Serratia isolated from blood samples of the patients in Namazi Hospital, Shiraz, Southern Iran. Iran. J. Microbiol. 5, 328-333.

Naas, T., Cuzon, G., Villegas, M.-V., Lartigue, M.-F., Quinn, J. P., and Nordmann, P. (2008). Genetic structures at the origin of acquisition of the beta-lactamase bla KPC gene. Antimicrob. Agents Chemother. 52, 1257-1263. doi: 10.1128/ AAC.01451-07

Nordmann, P., Naas, T., and Poirel, L. (2011). Global Spread of Carbapenemaseproducing Enterobacteriaceae. Emerg. Infect. Dis. 17, 1791-1798. doi: 10.3201/ eid1710.110655

O'Horo, J., Mahler, S. B., Gardner, B., and Berbari, E. F. (2017). Serratia and Surgical Site Infections: risk factors and Epidemiology. Open Forum Infect. Dis. 4, S650-S650. doi: 10.1093/ofid/ofx163.1730

Okoche, D., Asiimwe, B. B., Katabazi, F. A., Kato, L., and Najjuka, C. F. (2015). Prevalence and characterization of carbapenem-resistant Enterobacteriaceae Isolated from Mulago National Referral Hospital, Uganda. PLoS One 10:e0135745. doi: 10.1371/journal.pone.0135745

Phan, H. T. T., Stoesser, N., Maciuca, I. E., Toma, F., Szekely, E., Flonta, M., et al. (2018). Illumina short-read and MinION long-read WGS to characterize the molecular epidemiology of an NDM-1 Serratia marcescens outbreak in Romania. J. Antimicrob. Chemother. 73, 672-679. doi: 10.1093/jac/dkx456

Platell, J. L., Cobbold, R. N., Johnson, J. R., Heisig, A., Heisig, P., Clabots, C., et al. (2011). Commonality among fluoroquinolone-resistant sequence type ST131 extraintestinal Escherichia coli isolates from humans and companion animals in Australia. Antimicrob Agents Chemother. 55, 3782-3787. doi: 10.1128/AAC. 00306-11

Poirel, L., Cattoir, V., and Nordmann, P. (2012). Plasmid-mediated quinolone resistance; interactions between Human, Animal, and Environmental Ecologies. Front. Microbiol. 3:24.

Poirel, L., Dortet, L., Bernabeu, S., and Nordmann, P. (2011). Genetic features of blaNDM-1-Positive Enterobacteriaceae. Antimicrob. Agents Chemother. 55, 5403-5407. doi: 10.1128/AAC.00585-11

Queenan, A. M., and Bush, K. (2007). Carbapenemases: the Versatile betalactamases. Clin. Microbiol. Rev. 20, 440-458. doi: 10.1128/CMR.00001-07

Rawat, D., and Nair, D. (2010). Extended-spectrum B-lactamases in gram negative bacteria. J. Glob. Infect. Dis. 2, 263-274. doi: 10.4103/0974-777X.68531

Raymond, J., and Aujard, Y. (2000). Nosocomial infections in pediatric patients: a European, multicenter prospective study. European study group. Infect. Control Hosp. Epidemiol. 21, 260-263. doi: 10.1086/501755

Ribeiro, P. C. S., Monteiro, A. S., Marques, S. G., Monteiro, S. G., Monteiro-Neto, V., Coqueiro, M. M. M., et al. (2016). Phenotypic and molecular detection of the blaKPC gene in clinical isolates from inpatients at hospitals in São Luis, MA, Brazil. BMC Infect. Dis. 16:737. doi: 10.1186/s12879-016-2072-3

Ribeiro, V. B., Andrade, L. N., Linhares, A. R., Barin, J., Darini, A. L. D. C. Zavascki, A. P., et al. (2013). Molecular characterization of Klebsiella pneumoniae carbapenemase-producing isolates in southern Brazil. J. Med. Microbiol. 62, 1721-1727. doi: 10.1099/jmm.0.062141-0

Sader, H. S., Farrell, D. J., Flamm, R. K., and Jones, R. N. (2014). Antimicrobial susceptibility of Gram-negative organisms isolated from patients hospitalized in intensive care units in United States and European hospitals (2009-2011). Diagn. Microbiol. Infect. Dis. 78, 443-448. doi: 10.1016/j.diagmicrobio.2013.11. 025

Salini, R., and Pandian, S. K. (2015). Interference of quorum sensing in urinary pathogen Serratia marcescens by Anethum graveolens. Pathog. Dis. 73:ftv038. doi: $10.1093 /$ femspd/ftv038

Sandner-Miranda, L., Vinuesa, P., Cravioto, A., and Morales-Espinosa, R. (2018). The genomic basis of intrinsic and acquired antibiotic resistance in the genus Serratia. Front. Microbiol. 9:828. doi: 10.3389/fmicb.2018.00828

Seeyave, D., Desai, N., Miller, S., Rao, S. P., and Piecuch, S. (2006). Fatal delayed transfusion reaction in a sickle cell anemia patient with Serratia marcescens sepsis. J. Natl. Med. Assoc. 98, 1697-1699.

Shanks, R. M. Q., Lahr, R. M., Stella, N. A., Arena, K. E., Brothers, K. M., Kwak, D. H., et al. (2013). A Serratia marcescens PigP homolog controls prodigiosin biosynthesis, swarming motility and hemolysis and is regulated by cAMP-CRP and HexS. PLoS One 8:e57634. doi: 10.1371/journal.pone.0057634
Sheng, W. H., Chen, Y. C., Wang, J. T., Chang, S. C., Luh, K. T., and Hsieh, W. C. (2002). Emerging fluoroquinolone-resistance for common clinically important gram-negative bacteria in Taiwan. Diagn. Microbiol. Infect. Dis. 43, 141-147. doi: 10.1016/S0732-8893(02)00381-4

Silva, D. D. C., Rampelotto, R. F., Lorenzoni, V. V., Santos, S. O. D., Damer, J., Hörner, M., et al. (2017). Phenotypic methods for screening carbapenemresistant Enterobacteriaceae and assessment of their antimicrobial susceptibility profile. Rev. Soc. Bras. Med. Trop. 50, 173-178. doi: 10.1590/0037-8682-04712016

Silva, K. E., Cayô, R., Carvalhaes, C. G., Sacchi, F. P. C., Rodrigues-Costa, F., Da Silva, A. C. R., et al. (2015). Coproduction of KPC-2 and IMP-10 in Carbapenem-Resistant Serratia marcescens isolates from an outbreak in a Brazilian teaching hospital. J. Clin. Microbiol. 53, 2324-2328. doi: 10.1128/JCM. 00727-15

Srinivasan, R., Mohankumar, R., Kannappan, A., Karthick Raja, V., Archunan, G., Karutha Pandian, S., et al. (2017). Exploring the anti-quorum sensing and antibiofilm efficacy of phytol against Serratia marcescens associated acute pyelonephritis infection in Wistar rats. Front. Cell. Infect. Microbiol. 7:498. doi: $10.3389 /$ fcimb. 2017.00498

Stock, I., Grueger, T., and Wiedemann, B. (2003). Natural antibiotic susceptibility of strains of Serratia marcescens and the S. liquefaciens complex: S. liquefaciens sensu stricto, S. proteamaculans and S. grimesii. Int. J. Antimicrob. Agents 22, 35-47. doi: 10.1016/s0924-8579(02)00163-2

Sugumar, M., Kumar, K. M., Manoharan, A., Anbarasu, A., and Ramaiah, S. (2014). Detection of OXA-1 $\beta$-lactamase gene of Klebsiella pneumoniae from blood stream infections (BSI) by conventional PCR and in-silico analysis to understand the mechanism of OXA mediated resistance. PLoS One 9:e91800. doi: 10.1371/journal.pone.0091800

Tenover, F. C., Canton, R., Kop, J., Chan, R., Ryan, J., Weir, F., et al. (2013). Detection of Colonization by Carbapenemase-Producing Gram-Negative Bacilli in Patients by Use of the Xpert MDRO Assay. J. Clin. Microbiol. 51, 3780-3787. doi: 10.1128/JCM.01092-13

Tzouvelekis, L. S., Markogiannakis, A., Psichogiou, M., Tassios, P. T., and Daikos, G. L. (2012). Carbapenemases in Klebsiella pneumoniae and Other Enterobacteriaceae: an Evolving Crisis of Global Dimensions. Clin. Microbiol. Rev. 25, 682-707. doi: 10.1128/CMR.05035-11

Ulu-Kilic, A., Parkan, O., Ersoy, S., Koc, D., Percin, D., Onal, O., et al. (2013). Outbreak of postoperative empyema caused by Serratia marcescens in a thoracic surgery unit. J. Hosp. Infect. 85, 226-229. doi: 10.1016/j.jhin.2013.07.008

Us, E., Kutlu, H. H., Tekeli, A., Ocal, D., Cirpan, S., and Memikoglu, K. O. (2017). Wound and soft tissue infections of Serratia marcescens in patients receiving wound care: a health care-associated outbreak. Am. J. Infect. Control 45, 443-447. doi: 10.1016/j.ajic.2016.11.015

Veldman, K., Cavaco, L. M., Mevius, D., Battisti, A., Franco, A., Botteldoorn, N., et al. (2011). International collaborative study on the occurrence of plasmidmediated quinolone resistance in Salmonella enterica and Escherichia coli isolated from animals, humans, food and the environment in 13 European countries. J. Antimicrob. Chemother. 66, 1278-1286. doi: 10.1093/jac/dk r084

Versalovic, J., Schneider, M., De Bruijn, F. J., and Lupski, J. R. (1994). Genomic fingerprinting of bacteria using repetitive sequence-based polymerase chain reaction Meth. Mol. Cell. Biol. 5, 25-40. doi: 10.1128/JCM.43.1.199-207. 2005

Vetter, L., Schuepfer, G., Kuster, S. P., and Rossi, M. (2016). A Hospital-wide Outbreak of Serratia marcescens, and Ishikawa's "Fishbone" Analysis to Support Outbreak Control. Qual. Manag. Health Care 25, 1-7. doi: 10.1097/QMH. 0000000000000078

von Wintersdorff, C. J., Penders, J., van Niekerk, J. M., Mills, N. D., Majumder, S., van Alphen, L. B., et al. (2016). Dissemination of antimicrobial resistance in microbial ecosystems through horizontal gene transfer. Front. Microbiol. 19:173. doi: 10.3389/fmicb.2016.00173

Wong, M. H., Chan, E. W., Liu, L. Z., and Chen, S. (2014). PMQR genes oqxAB and $\mathrm{aac}\left(6^{\prime}\right) \mathrm{Ib}-\mathrm{cr}$ accelerate the development of fluoroquinolone resistance in Salmonella typhimurium. Front. Microbiol. 5:521. doi: 10.3389/fmicb.2014. 00521

Xiong, Z., Li, T., Xu, Y., and Li, J. (2007). Detection of CTX-M-14 extendedspectrum $\beta$-lactamase in Shigella sonnei isolates from China. J. Infect. 55, e125-e128. doi: 10.1016/j.jinf.2007.07.017 
Yan, B. C., Westfall, B. A., and Orlean, P. (2001). Ynl038wp (Gpi15p) is the Saccharomyces cerevisiae homologue of human Pig-Hp and participates in the first step in glycosylphosphatidylinositol assembly. Yeast 18, 1383-1389. doi: $10.1002 /$ yea.783

Yoon, H. J., Choi, J. Y., Park, Y. S., Kim, C. O., Kim, J. M., Yong, D. E., et al. (2005). Outbreaks of Serratia marcescens bacteriuria in a neurosurgical intensive care unit of a tertiary care teaching hospital: a clinical, epidemiologic, and laboratory perspective. Am. J. Infect. Control 33, 595-601. doi: 10.1016/j.ajic.2005.01.010

Young, V. M., Moody, M. R., and Morris, M. J. (1980). Distribution of Serratia marcescens serotypes in cancer patients. J. Med. Microbiol. 13, 333-339. doi: 10.1099/00222615-13-2-333

Yu, W. L., Lin, C. W., and Wang, D. Y. (1998). Serratia marcescens bacteremia: clinical features and antimicrobial susceptibilities of the isolates. J. Microbiol. Immunol. Infect. 31, 171-179.

Yu, W. L., Wu, L. T., Pfaller, M. A., Winokur, P. L., and Jones, R. N. (2003). Confirmation of extended-spectrum beta-lactamase-producing Serratia marcescens: preliminary report from Taiwan. Diagn. Microbiol. Infect. Dis. 45, 221-224. doi: 10.1016/s0732-8893(02)00539-4
Zingg, W., Soulake, I., Baud, D., Huttner, B., Pfister, R., Renzi, G., et al. (2017). Management and investigation of a Serratia marcescens outbreak in a neonatal unit in Switzerland - the role of hand hygiene and whole genome sequencing. Antimicrob. Resist. Infect. Control 6:125. doi: 10.1186/s13756-0170285-x

Conflict of Interest: The authors declare that the research was conducted in the absence of any commercial or financial relationships that could be construed as a potential conflict of interest.

Copyright (๑) 2020 Ferreira, Rezende, Damas, Oliveira-Silva, Pitondo-Silva, Brito, Leonardecz, Góes, Campanini, Malavazi, da Cunha and Pranchevicius. This is an open-access article distributed under the terms of the Creative Commons Attribution License (CC BY). The use, distribution or reproduction in other forums is permitted, provided the original author(s) and the copyright owner(s) are credited and that the original publication in this journal is cited, in accordance with accepted academic practice. No use, distribution or reproduction is permitted which does not comply with these terms. 